\title{
Comment
}

Cerebrovascular Diseases

Cerebrovasc Dis 2011;32:383-384

DOI: $\underline{10.1159 / 000331464}$

\section{Looking through the PRISM: New Insights for Young Patients with Atrial Fibrillation and Stroke}

\author{
Amitava Banerjee, Gregory Y.H. Lip \\ University of Birmingham Centre for Cardiovascular Sciences, \\ City Hospital, Birmingham, UK
}

The scale of the global burden of stroke is unquestionable and future increases are predicted with changing demography and ageing populations [1,2]. As a major risk factor for stroke [3] and as a cause of morbidity and mortality in its own right, atrial fibrillation (AF) represents an opportunity for both primary and secondary prevention against stroke [4], where patients with one or more stroke risk factors should be considered for thromboprophylaxis [5]. Indeed, tremendous advances have taken place and continue to occur in how we approach thromboprophylaxis in AF by balancing stroke and bleeding risk [6-9].

In order to implement this knowledge, reliable data about the risk factors and outcomes of AF must be gathered at several levels from clinical trials and single-centre studies to analyses at the health system level in 'real-world' populations. As demographic factors and treatment guidelines and practices change, there is also a growing need for surveillance data [1].

In this issue, Gatellari et al. [10] report a study of adult in-hospital stroke admissions in New South Wales and the outcomes related to concomitant AF between 2000 and 2006 from A Program of Research Informing Stroke Management (PRISM). They found that $25.4 \%$ of 26,960 patients with ischaemic stroke had AF recorded during admission, which is comparable to previous studies. The authors are to be commended on this timely largescale study which illustrates the potential utility of analyses at health system level.

The PRISM study confirms several well-characterised features of AF in the setting of stroke. First, AF prevalence and rates of all complications increased with age. Second, AF patients were more likely to suffer complications of every type and mortality than stroke patients without AF. Third, AF patients are more likely to have comorbidities, such as hypertension and heart failure, and these comorbidities increase with age.

Risk stratification scores have been validated for AF and risk of stroke and are increasingly used by clinicians in order to assess and individualise patient risk [11]. Gatellari et al. [10] assessed the pre-admission risk of stroke (using $\mathrm{CHADS}_{2}$ [12] and $\mathrm{CHA}_{2} \mathrm{DS}_{2}-$ VASc [13] scores) and bleeding (using the HAS-BLED score [14]). As shown in other real-world populations [11], the $\mathrm{CHA}_{2} \mathrm{DS}_{2}$ VASc score stratified more patients at high stroke risk than the
$\mathrm{CHADS}_{2}$ score. A substantial proportion of patients at 'high risk' in both risk scoring schemes were not on anticoagulation, despite very few patients having HAS-BLED scores of $\geq 3$, which would signify high bleeding risk.

Gatellari et al. [10] considered the potentially modifying effect of age, sex and comorbidity on the association between AF and outcomes. Interestingly, although increased age was associated with increasing mortality, this interaction effect illustrated that the differences in mortality between AF and non-AF stroke decreased with increasing age. In other words, the effect of AF versus non-AF in stroke patients was greatest in young patients. At 30 days, the relative risk of mortality due to AF was 3.16 (95\% CI 1.92-5.25) amongst those younger than 50, decreasing to 1.23 (95\% CI 1.13-1.33) in patients aged $>85$ years. Moreover, the differences in proportion of patients needing rehabilitation and length of hospital stay between AF and non-AF patients were greatest in younger patients ( $\mathrm{p}$ value interaction $<0.0006$ and $<0.0001$ respectively).

Young patients with stroke and AF clearly represent an underrecognised 'at-risk' population [15]. In the PRISM study, half of AF-related stroke patients aged $<65$ years had a $\mathrm{CHA}_{2} \mathrm{DS}_{2}$-VASc score of $\geq 2(51.3 \%)$ and $39.8 \%$ had a CHADS 2 score of $\geq 2$, signifying a high risk of stroke [10]. We do know that AF patients in 'realworld' clinical practice receiving antiplatelet/no therapy have much higher rates of ischaemic stroke than patients receiving anticoagulation [16]. Antiplatelet therapy and no therapy are associated with similar bleeding rates to oral anticoagulation, especially in the elderly [4]. Therefore, there is a strong argument in terms of stroke prevention for increasing the utilisation of anticoagulants in clinical practice, given current under-treatment rates [16]. One recent analysis examining the net clinical benefit balancing the risk of ischaemic stroke and intracranial haemorrhage found a neutral or positive net clinical benefit (ischaemic stroke vs. intracranial haemorrhage) with oral anticoagulation in patients with a $\mathrm{CHADS}_{2}$ score of $\geq 0$, and $\mathrm{CHA}_{2} \mathrm{DS}_{2}$-VASc score of $\geq 1$, whilst there was a negative net clinical benefit at a $\mathrm{CHA}_{2} \mathrm{DS}_{2}$-VASc score $=0$ (reflecting the 'truly low risk' status of these patients) [17]. Indeed, the net clinical benefit was even greater at HAS-BLED scores of $\geq 3$.

Further studies of young stroke patients with AF are warranted in order to establish potential differences in aetiology and pathophysiology of stroke compared with older stroke patients with AF, as illustrated by the study by Gatellari et al. [10]. Such patients may require different diagnostic and treatment strategies. For example, in a recent hospital-based cohort study of French patients with AF, the risk of stroke and thromboembolism was independently increased by the presence of heart failure, previous stroke, or vascular disease in patients $<65$ years of age [18], suggesting that these factors are particularly important in younger AF patients.

\section{KARGER}

Fax +41613061234 E-Mail karger@karger.ch www.karger.com
(อ) 2011 S. Karger AG, Basel

$1015-9770 / 11 / 0324-0383 \$ 38.00 / 0$ 
With the advent of novel anticoagulants [19,20], there are new therapeutic options without the potential harms of warfarin, particularly for younger patients with indications for lifelong anticoagulation. Future clinical trials and prospective cohort analyses of new treatments should be statistically powered to consider the comparative effectiveness of treatment in younger patients. Although the major increase in burden of stroke and AF will be a result of ageing populations, the importance of stroke prevention in young AF patients must not be neglected. Things can only improve.

\section{References}

1 Johnston SC, Mendis S, Mathers CD: Global variation in stroke burden and mortality: estimates from monitoring, surveillance, and modelling. Lancet Neurol 2009;8:345-354.

2 Kirchhof P, Bax J, Blomstrom-Lundquist C, Calkins H, Camm AJ, Cappato R, Cosio F, Crijns H, Diener HC, Goette A, Israel CW, Kuck KH, Lip GY, Nattel S, Page RL, Ravens U, Schotten U, Steinbeck G, Vardas P, Waldo A, Wegscheider K, Willems S, Breithardt G: Early and comprehensive management of atrial fibrillation: proceedings from the $2 \mathrm{nd}$ AFNET/EHRA Consensus Conference on Atrial Fibrillation entitled 'Research Perspectives in Atrial Fibrillation'. Europace 2009;11:860 885.

-3 Abegunde DO, Mathers CD, Adam T, Ortegon M, Strong K: The burden and costs of chronic diseases in low-income and middle-income countries. Lancet 2007;370:1929-1938.

4 Camm AJ, Kirchhof P, Lip GY, Schotten U, Savelieva I, Ernst S, Van Gelder IC, Al-Attar N, Hindricks G, Prendergast B, Heidbuchel H, Alfieri O, Angelini A, Atar D, Colonna P, De Caterina R, De Sutter J, Goette A, Gorenek B, Heldal M, Hohloser SH, Kolh P, Le Heuzey JY, Ponikowski P, Rutten FH: Guidelines for the management of atrial fibrillation: the Task Force for the Management of Atrial Fibrillation of the European Society of Cardiology (ESC). Eur Heart J 2010;31:23692429 .

-5 Gorin L, Fauchier L, Nonin E, de Labriolle A, Haguenoer K, Cosnay P, Babuty D, Charbonnier B: Antithrombotic treatment and the risk of death and stroke in patients with atrial fibrillation and a CHADS2 score $=1$. Thromb Haemost 2010;103:833-840.

6 Lip GY: Anticoagulation therapy and the risk of stroke in patients with atrial fibrillation at 'moderate risk' (CHADS2 score $=1$ ): simplifying stroke risk assessment and thromboprophylaxis in real-life clinical practice. Thromb Haemost 2010;103:683-685.

7 Garcia DA, Lopes RD, Hylek EM: New-onset atrial fibrillation and warfarin initiation: high-risk periods and implications for new antithrombotic drugs. Thromb Haemost 2010;104:1099-1105.

-8 Prystowsky EN, Camm J, Lip GY, Allessie M, Bergmann JF, Breithardt G, Brugada J, Crijns H, Ellinor PT, Mark D, Naccarelli G, Packer D, Tamargo J: The impact of new and emerging clinical data on treatment strategies for atrial fibrillation. J Cardiovasc Electrophysiol 2010;21 946-958.
\9 Lip GY, Andreotti F, Fauchier L, Huber K, Hylek E, Knight E, Lane DA, Levi M, Marin F, Palareti G, Kirchhof P; Document reviewers: Collet JP, Rubboli A, Poli D, Camm J: Bleeding risk assessment and management in atrial fibrillation patients: a position document from the European Heart Rhythm Association, endorsed by the European Society of Cardiology Working Group on Thrombosis. Europace 2011;13:723746

10 Gatellari M, Goumas C, Aitken R, Worthington JM: Outcomes for patients with ischaemic stroke and atrial fibrillation: the PRISM study (a program of research informing stroke management). Cerebrovasc Dis 2011;32:370-382.

11 Olesen J, Lip GYH, Hansen ML, et al: Validation of risk stratification schemes for predicting stroke and thromboembolism in patients with atrial fibrillation: a nationwide cohort study. BMJ 2011;342:d124.

12 Gage BF, Waterman AD, Shannon W, Boechler M, Rich MW, Radford MJ: Validation of clinical classification schemes for predicting stroke: results from the National Registry of Atrial Fibrillation. JAMA 2001; 285:2864-2870.

13 Lip GY, Nieuwlaat R, Pisters R, Lane DA, Crijns HJ: Refining clinical risk stratification for predicting stroke and thromboembolism in atrial fibrillation using a novel risk factor-based approach: the Euro Heart Survey on atrial fibrillation. Chest 2010;137:263-272.

14 Pisters R, Lane DA, Nieuwlaat R, de Vos CB, Crijns HJ, Lip GY: A novel user-friendly score (HAS-BLED) to assess 1-year risk of major bleeding in patients with atrial fibrillation: the Euro Heart Survey. Chest 2010;138:1093-1100.

15 Ferro JM, Massaro AR, Mas JL: Aetiological diagnosis of ischaemic stroke in young adults. Lancet Neurol 2010;9:1085-1096.

16 Ogilvie IM, Welner SA, Cowell W, Lip GY: Ischaemic stroke and bleeding rates in 'real-world' atrial fibrillation patients. Thromb Haemost 2011;106:34-44

17 Olesen JB, Lip GYH, Lindhardsen J, et al: Risks of thromboembolism and bleeding with thromboprophylaxis in patients with AF: a net clinical benefit analysis in a 'real-world' nationwide cohort study. Thromb Haemostat 2011;20:106.

18 Olesen JB, Fauchier L, Lane DA, Taillandier S, Lip GY: Risk factors for stroke and thromboembolism in relation to age amongst patients with atrial fibrillation: The Loire Valley Atrial Fibrillation Project. Chest 2011 (E-pub ahead of print).

19 Ahrens I, Lip GY, Peter K: New oral anticoagulant drugs in cardiovascular disease. Thromb Haemost 2010;104:49-60.

20 Roskell NS, Lip GY, Noack H, Clemens A, Plumb JM: Treatments for stroke prevention in atrial fibrillation: a network meta-analysis and indirect comparisons versus dabigatran etexilate. Thromb Haemost 2010;104:1106-1115.

Prof. G.Y.H. Lip

University of Birmingham Centre for Cardiovascular Sciences

City Hospital, Birmingham B18 7QH (UK)

Tel. +44 1215075080

E-Mail g.y.h.lip@bham.ac.uk 